\title{
Malay ESL Students’ Difficulties in Using English Prepositions
}

\author{
Loi Chek Kim, Songyut Akkakoson, Mehmet Cem Odacıŏlu, Norazah Mohd Suki, and Henry Bating
}

\begin{abstract}
The study attempts to undertake an error analysis of prepositions employed in the written work of Form 4 Malay ESL (English as a Second Language) students in Malaysia. The error analysis was undertaken using Richards's (1974) framework of intralingual and interlingual errors and Bennett's (1975) framework in identifying prepositional concepts found in the sample. The study first identified common prepositional errors in the written texts of 150 student participants. It then measured the relative intensities of these errors and found out possible causes for the occurrences of these errors. In this study, one significant finding is that among the nine concepts of prepositions examined, the participant students tended to make the most number of errors in the use of prepositions of time and place. The present study has pedagogical implications in teaching English prepositions to Malay ESL students.
\end{abstract}

Index Terms-Interlingual, intralingual errors, malay, prepositional errors.

\section{INTRODUCTION}

ESL (English as a Second Language) students manifest many and a wide range of grammatical errors in their second language. One of the most likely common errors is in the use of prepositions. A preposition is a word that shows the relationship between two words in a sentence. The relationships cover those of time, direction, position and different degrees of mental and emotional states [1]. Due to the difficulties in the use of prepositions, language teachers try to adopt different approaches and methods to teach prepositions so the learning process can be made more efficient for students. Very often learners' errors may not viewed as beneficial elements in language teaching itself. However, errors are viewed as a natural and integral phenomenon in the process of second language learning [2]. Whether in speech or writing, errors are necessary for learning [3] and this indicates that actual learning is taking place [2]. In addition, an error analysis may reveal the strategies attempted by learners to master the target language. By knowing students' weaknesses and causes of these errors, the language teacher will be in a better position to use effective teaching materials and teaching approaches to help

Manuscript received June 28, 2017; revised September 10, 2017.

C. K. Loi, Norazah Mohd Suki and H. Bating are with the Universiti Malaysia Sabah, Jalan Sungai Pagar, 87000 Wilayah Persekutuan Labuan, Malaysia (e-mail: loick@ums.edu.my, azahsuki@yahoo.com, hbating@gmail.com).

S. Akkakoson is with King Mongkut's University of Technology North Bangkok (KMUTNB), Thailand (e-mail: songyutbee@gmail.com).

M. C. Odacıoğlu is with the Bartın University, Turkey (e-mail: codacioglu@sakarya.edu.tr). students overcome the difficulties in learning prepositions [4]. In a similar note, [5] claimed that the analysis of errors made by language learners represents "the most significant data on which a construction of his knowledge of the target language could be made" (p. 72). Through error analysis, a list of common errors can provide the basis for the material selection to be incorporated into the language syllabus.

In general, most past research on error analysis has been carried out to identify and categorize errors as well as tabulate frequency counts of these errors. Three of earlier studies undertaken to investigate errors made by students in Malaysia are by [6]-[8], [6] undertook an error analysis on English nouns and verb phrases using an error analysis approach. His subjects consisted of 320 Form 1 and Form 2 Malay ESL students in Malaysia. Each student was asked to write two essays (narrative and descriptive). The error analysis involved nouns and pronouns. All these errors were classified based on a description of forms, namely total omission of forms, total wrong forms, total insertion forms and wrong word order [7] examined errors occurred in the essays written by Standard 4, 5 and 6 pupils in a primary school in Kuala Lumpur. Errors have been categorized under the main headings of punctuation, capitalization, word form, structure and spelling. In a study undertaken among undergraduate students, [8] looked at errors found in the examination scripts of students from the Science and Islamic Faculties at Universiti Kebangsaan Malaysia. Her analysis shows that interference errors primarily occurred in the areas of prepositions, variable nouns, articles genitives, spelling and tenses.

In another study, the findings showed that prepositional errors were found as one of the most frequent errors made by ESL learners [9] examined errors in English essays written by forty Form 2 Chinese-educated students. Prepositional errors formed the third largest group of word class errors (11.8\%). Wrong selection of prepositions accounted for more than half the errors. This was followed by unnecessary insertion of prepositions and omission of prepositions. [9] held that prepositional errors found in the work of Chinese-educated students were resulted from students applying features peculiar to Chinese prepositions to English prepositions, mother tongue interference and various functions of English prepositions, a feature not found in Chinese prepositions.

In another study by [10] which examined the English syntactic problems persistent in the written work of native Arabic-speaking freshmen English language class of a university, he claimed that prepositions were found with greatest repeated number of errors in the corpus The above findings plus those in some past studies (e.g. [1]; [11]-[13]) 
show that learners found great difficulty in learning prepositions. In addition, [14] held that the sheer number of English prepositions and their polysemous nature contribute to the difficulty in learning English prepositions among learners. According to [15], polysemy is "a semantic characteristic of words that have multiple meanings” (p. 299) The differing meanings are context-dependent. Thus, prepositional usage among ESL/EFL (English as a Foreign Language) students has been found to be worthy of its study. The research questions formulated in this study are:

(i) Based on the frequency of errors tabulated, which concept of prepositional meaning poses the most problem for Malay ESL students?

(ii) What are the plausible causes for the prepositional errors?

(iii) What measures can be taken to minimize the learning difficulties of English prepositions among Malay ESL students?

\section{Methodology}

The subjects of this study consisted of 150 sixteen-year old students randomly selected from four Form 4 classes at a secondary school in Selangor, Malaysia. All of the student participants are Malay ESL students whose native language is Bahasa Malaysia.

A test which comprised two major sections, namely a composition and a grammar test was designed for these students in the study. Students were asked to write a composition of not more than 350 words in the class. The given essay title was "The most horrible day in my life".

For the grammar test, worksheets consisting of a cloze test and sentence completion were given. Choices of prepositions were provided and students were asked to fill in the blanks by choosing the correct prepositions. The time allocated for the composition writing and the grammar test was one and a half hours. A total of 150 compositions with a total running word count of 22000 words and 150 worksheets were collected as the student samples on which an error analysis was undertaken.

The error analysis was undertaken using [16]'s framework and [17]'s framework [16] expressed that errors occur frequently regardless of the learner's background. He also contends that these errors do not necessarily reflect the learner's inability to separate two languages but such errors reflect the learner's competence at a particular stage in his attempt to study the language. According to [16], these errors are caused firstly within the structure of the English language itself (intralingual errors) and secondly, through reference to the strategy by which a second language is acquired and taught (interlingual errors). Intralingual errors are further sub-categorized into, namely (i) overgeneralization (ii) ignorance of rule restriction (iii) incomplete application of rules and (iv) false concept hypothesized.

Interlingual errors are attributed to the phenomenon of language transfer. A positive transfer reflects that a certain feature of the two languages matches exactly while a negative transfer (interference) shows a certain feature of the two languages does not match/agree exactly [17]'s framework on the other hand was used to identify the prepositional meanings/concepts found in the sample [17] identified several common prepositional meanings including locative, directional, comitative, dative, benefactive, instrumental, genitive, causal and manner. These meanings can be grouped as prepositions of place or position, prepositions of direction, preposition of time, prepositions of purpose, prepositions of association, prepositions of similarity, prepositions used with means of transport, prepositions of agent/source, prepositions of accompaniment 'with' and prepositions with comparative forms.

The method of analysis consisted of the following four stages namely (i) identification of prepositional errors (ii) categorization and subcategorization of prepositional errors framework (iii) tabulation of frequency count and (iv) description and explanation of common prepositional errors.

\section{RESUlTS AND DisCUSSION}

A total of 1457 errors were found in the sample, with more errors in the grammar tests (1117 errors) and fewer in the compositions (340 errors).

Table I shows the distribution of the prepositional errors in both the tests and the compositions. Fig. 1 shows the total distribution of errors in the nine concepts of prepositional meanings found in the data.

The highest frequency of errors involved the concept of time with a total of 245 errors (17\%). From here, it can be observed that the subjects may find it extremely difficult to learn and apply the preposition of time correctly. This finding corresponds to the conclusion made by [18], [19] that the frequency of errors is proportional to the degree of language difficulty.

The next concept of errors was the prepositions of place, which charted 21 errors (15.2\%) followed by the concept of direction (204 errors; 14\%). The concepts of verb-preposition and manner-agent yielded 201 errors (13.8\%) and 195 errors (13.4\%) respectively. The other two were the concepts of adjective-preposition and cause-purpose. The former had 193 errors (13\%) while the latter had 89 errors (6.1\%). This is followed by the concepts of similarity (64 errors; 4.4\%) and association (45 errors; $3.1 \%$ ) forming the two relatively low frequency of errors. The lower frequency of errors for the concepts of similarity and association compared to the other concepts indicated that the subjects most probably had a clearer understanding of and were more familiar with the use of the concepts of similarity and association.

TABLE I: DISTRIBUTION OF PREPOSTIONAL ERRORS IN THE SAMPLE

\begin{tabular}{|c|c|c|c|c|}
\hline $\begin{array}{c}\text { Categories of } \\
\text { Prepositions }\end{array}$ & Worksheet & Composition & Total & $\%$ \\
\hline place & 170 & 51 & 221 & 15.2 \\
\hline direction & 141 & 63 & 204 & 14.0 \\
\hline time & 199 & 46 & 245 & 17.0 \\
\hline manner-agent & 147 & 48 & 195 & 13.4 \\
\hline cause-purpose & 60 & 29 & 89 & 6.1 \\
\hline similarity & 51 & 13 & 64 & 4.4 \\
\hline association & 36 & 9 & 45 & 3.1 \\
\hline verb-preposition & 169 & 32 & 201 & 13.8 \\
\hline Adjective-preposition & 144 & 49 & 193 & 13 \\
\hline Total & 1117 & 340 & 1457 & 100 \\
\hline
\end{tabular}


Most of the prepositional errors occurred in the sub-category of wrong selection (1362 errors; 95\%). This was followed by the sub-category of omission (61 errors; 4\%) and the least errors occurred in the sub-category of insertion with only 34 errors (1\%). The results are shown in Fig. 2.

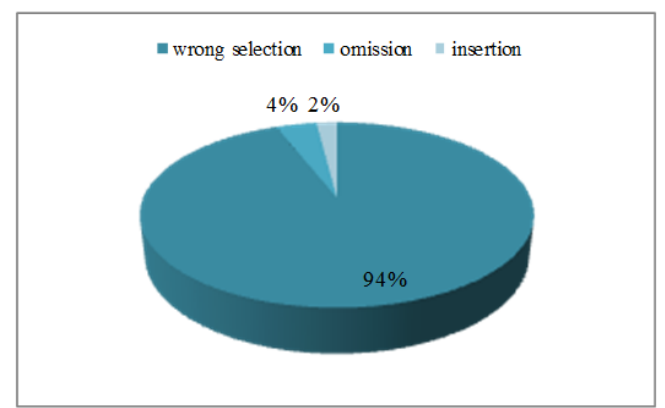

Fig. 2. Percentage of prepositional errors in the three sub-categories.

The breakdown for these three sub-categories is tabulated in the following Table II.

TABLE II: PREPOSTIONAL ERRORS IN THE THREE SUB-CATEGORIES

\begin{tabular}{|c|c|c|c|c|c|}
\hline $\begin{array}{c}\text { Categories of } \\
\text { prepositions }\end{array}$ & $\begin{array}{c}\text { Wrong } \\
\text { selection }\end{array}$ & Omission & $\begin{array}{c}\text { Unnecessary } \\
\text { insertion }\end{array}$ & Total & $\%$ \\
\hline Time & 223 & 16 & 6 & 245 & 17 \\
\hline Place & 203 & 8 & 10 & 221 & 15.2 \\
\hline Direction & 193 & 8 & 3 & 204 & 14 \\
\hline Verb-prep & 194 & 3 & 4 & 201 & 13.8 \\
\hline Manner-agent & 181 & 10 & 4 & 195 & 13.4 \\
\hline Adj-prep & 189 & 4 & 0 & 193 & 13 \\
\hline Cause-purpose & 81 & 3 & 5 & 89 & 6.1 \\
\hline Similarity & 64 & 0 & 0 & 64 & 4.4 \\
\hline Association & 34 & 9 & 2 & 45 & 3.1 \\
\hline Total & 1362 & 61 & 34 & 1457 & 100 \\
\hline \% & 94 & 4 & 2 & & \\
\hline
\end{tabular}

As shown in Table II, out of 1457 errors identified in the sample, the majority of these errors were contributed by the sub-category of wrong selection (1362 errors, 94\%). In this sub-category, prepositions of time and prepositions of place yielded the two highest frequency of errors with 223 errors and 203 errors respectively. This was followed by the sub-category of omission with 61 errors (4\%). In this sub-category, prepositions of time and manner-agent yielded the two highest frequency of errors with 16 errors and 10 errors respectively. The sub-category of unnecessary insertion yielded the least number of errors with only 34 errors (2\%) and the prepositions of place and time contributed to the two highest frequencies of errors with 10 errors and 6 errors respectively compared to other categories of prepositions. Some common examples from the sample for each of these three categories are presented and explained below. As prepositions of time and place yielded the two highest frequencies of errors among the nine categories of prepositions, more examples from these two categories are selected for illustration. Examples of 'wrong insertion' are firstly presented followed by those of 'wrong selection', 'omission' and 'unnecessary insertion'.

\section{A. Wrong Insertions of 'in' (Preposition of Place)}

'In' was replaced by 'at' and 'on'. Some common examples found in the sample are as follows: (i) There are many lakes *at (in) Taman Tasik.

(ii) We stay *at (in) Selangor.

(iii) In the forest, we slept *on (in) the camp.

The above errors could be due to the students' L1 (first language) interference. In Bahasa Malaysia, 'di' is used before a noun to indicate a place. The correspondent English preposition for 'di' is 'at'. However, in English, three prepositions, namely 'in', 'on' and 'at' are used to indicate a place, for example, 'at Jalan Puchong', 'in Selangor' and 'on the island'. Making a correct choice of the preposition to fit into a sentence may not be an easy task for the Malay ESL students considering in their mother tongue, only one preposition 'di' is used to indicate a place. Thus, negative transfer from their L1 to the target language could be a contributing factor to such errors.

The use of 'at' instead of 'in' may also due to 'overgeneralization' of a certain linguistic feature in the target language. In this case, the overgeneralization of 'at' appears before a geographical place. These students may have come across expressions such as 'at Jalan Puchong', 'at the restaurant', 'at home', 'at the beach', etc.

\section{B. Wrong Selection of 'at' (Preposition of Place)}

The preposition 'at' was replaced by other prepositions. Among those, 'to' and 'on' were the two most prominent ones. Some of the examples of errors in this category are presented below:

(iv) We arrived *to (at) the school.

(v) We arrive *on (at) Kuantan at $4 \mathrm{pm}$.

In (iv), an overgeneralization in the use of 'to' was that the preposition is used to connect an action to its destination or goal, for example,

(vi) She walked to the nearby supermarket

(vii) He tiptoed to his room.

(viii)He went to his relative's house.

(ix) They moved to a new house recently.

Malay learners' generalization of the above sentence patterns appears to have resulted in their application of 'to' to an inappropriate context [e.g. We arrived *to (at) the school]. Another possible explanation could be that students were confused in the application of the three corresponding English prepositions (i.e. 'in', 'on' and 'at') for 'di' [e.g. We arrived *on (at) Kuantan at $4 \mathrm{pm}$ ]. The following examples show the use of these three corresponding English prepositions:

Di restoran itu (at the restaurant)

Di pantai itu (at/on the beach)

Di Melaka (in Melaka)

Thus, Malay students could have made the prepositional error 'We arrive *on (at) Kuantan at 4 pm' as a result of the confusion in the use of the correct corresponding English preposition to replace 'di'(at).

\section{Wrong Selection of 'on' (Preposition of Time)}

'For', 'at' and 'in' were used to replace 'on'. Some common examples found in the sample are presented below:

(x) *For (on) the first day, we went for sightseeing in town.

(xi) "At (On) the second day, we went for sightseeing in town. 
(xii) It was sunny *at (on) the last day.

(xiii) I went to the trip *in (on) $3^{\text {rd }}$ December 2000.

(xiv) *At (on) that day, I was very ill.

One possible explanation for the above errors is the L1 interference in the target language (see also [20]). Malay students may have been influenced by the use of the Malay preposition 'pada'. In the Malay language, 'pada' is commonly used to express time. However, there are several types of time prepositions in English (e.g. 'in', 'on' and 'at'). 'In', 'on' and 'at' have their own rules of use. 'In' is commonly used to refer to month and year (e.g. in July, in 2017). 'On' is used for days of the week. (e.g. on Thursday) while 'at' is normally used to indicate a point of time (e.g. at $6 \mathrm{pm}$, at noon).

Another possible cause for the errors in this subcategory is overgeneralization in the use of specific English prepositions to inappropriate sentence contexts. For example, 'at that moment', and 'at that time' are grammatically correct but when 'at' is employed in an appropriate context (see examples x-xiv above), deviant structures are produced.

\section{Wrong Selection of 'in' (Preposition of Time)}

'At' and 'on' were used to substitute 'in' in the sample. Some of the common errors are presented below:

(xv) *At (In) the morning, we went for jogging.

(xvi) We played football *at (in) the evening.

(xvii) *On (In) the afternoon, we took a nap.

(xviii) They went to the trip *on (in) December 1999.

The errors could be due to overgeneralization in the use of 'at'. Malay students may have come across expressions such as 'at noon' and 'at night'. Both 'noon' and 'night' are nouns which show the notion of time. Therefore, by overgeneralizing, students employed 'at' for other temporal nouns as well. This phenomenon resulted in deviant structures as presented in examples (xv) to (xvii) above. The error in example (xviii) could be due to incomplete learning. Malay learners may have been confused by the use of 'in' and 'on'. The former is used for month (e.g. in December) and the latter is for date (e.g. on $2^{\text {nd }}$ December).

These errors can also be due to L1 interference in the target language. In the Malay grammar rules, 'pada' is placed before any temporal noun. However, in English, three different prepositions 'on', 'in' and 'at' are employed for temporal nouns. By perceiving or assuming there is only one English preposition for temporal nouns as in their L1, deviant structures were produced.

E. Wrong Selection of 'on' and 'in' (Prepositions of Manner-agent)

Some of the common errors are as follows:

(xix) Both of them travel *with (on) a camel.

(xx) A portrait done *by (in) charcoal.

These errors are probably due to the ignorance of rule restriction. Malay learners may have come across common prepositional phrases consisting of a verb and a preposition (e.g. We travel with him; He travels with his wife; This model is done by Ali; This work is done by them). Without knowing the rule restriction of the target language, Malay learners may have generalized and applied the same rule to another sentence of a different context, meaning and function.
They may have perceived that the preposition 'with' comes after the verb 'travel' and the preposition 'by' comes after 'done'. Thus, deviant structures in examples (xix) and (xx) were formed when they collaborated the same preposition with the same verb (i.e. 'travel with' and ‘done by') although the rule does not apply in the sentence context.

\section{F. Omission of 'at' (Preposition of Place)}

A verb which takes a preposition is semantically associated with another verb, which is not followed by a preposition. The following example (xxii) from the sample illustrates this phenomenon:

(xxi) They reached KLIA at $4 \mathrm{pm}$.

(xxii) They arrived $\wedge$ (arrived at) KLIA.

The verb 'arrived' is semantically associated with the verb 'reached'. Based on this association, Malay learners may have concluded that similar to the verb 'reached', there is no need for the verb 'arrived' to be followed by the preposition 'at'. By omitting 'at' after the verb 'arrived' resulted in the production of a deviant structure.

\section{G. Omission of 'of' (Preposition of Cause-purpose)}

Errors on the omission of 'of' could be due to L1 interference. Some examples of these errors are as follows:

(xxiii) We did not go out *because $\wedge$ (of) the rain.

(xxiv) He met with an accident *as a result $\wedge$ (of) his carelessness.

The negative transfer from L1 to target language has probably caused Malay learners to omit the preposition 'of'. In Malay, no preposition is needed in the construction of the above sentences (xxiii and xxiv). This is because 'kerana' (because) is sufficient to indicate the reason. For example, "Kita tidak keluar kerana hujan" [We did not go out *because ${ }^{\wedge}$ (of) the rain). On the other hand, in the English version of the sentence, placement of the preposition 'of' after the word 'because' is mandatory.

\section{H. Unnecessary Insertion of 'at' (Preposition of Place)}

Such errors can be attributed to the interference of a particular grammatical feature in the Malay language. Some examples of the errors found in the sample are presented below:

(xxv) We reached * “at” Genting Highlands.

(xxvi) We went to the swimming pool to swim * "at" there.

Students may have used the translation method in the use of the above preposition. That is, they translated the above English sentence into the Malay version "Kami sampai di Genting Highland”. In sentence (xxvi), incorrect semantic association could be the cause of the error. This means that a verb that takes no preposition is associated semantically with one which is followed by a preposition. As shown below, 'arrived' takes a preposition while 'reached' does not. However, since 'reached' is semantically associated with 'arrived', 'reached' is then considered as a verb that takes the preposition 'at' as well:

They arrived at Genting Highland

They reached * "at” Genting Highland.

\section{Unnecessary Insertion of 'in' (Preposition of Time)}

Some examples of unnecessary insertion of 'in' are as follows: 
(xxvii) We had to sit for another paper * “in" the next period.

(xxviii) They went for sightseeing * “in" the next day.

The insertion of 'in' is interpreted as the result of negative transfer from L1 to the target language. When students translated "pada keesokan hari" to "in the next day", they may have applied the same grammatical L1 rule (i.e. a preposition is needed before a temporal noun) to English. This resulted in the deviant structures in (xxvii) and (xxviii).

This error can also be traced to incomplete learning in English. In English, a preposition is commonly placed before a temporal noun/temporal noun phrase (e.g. on Wednesday, in January, on tomorrow morning). However, a preposition is redundant before certain temporal noun phrases such as 'the next day'. Students made such errors when they are not aware of the grammatical rule exception.

J. Unnecessary Insertion of 'between' and 'among' (Preposition of Association)

Two examples of the unnecessary insertion of 'between' and 'among' in the category of preposition of association are presented below:

$(\mathrm{xxix})^{*}$ "Between" Ali and Siti are acquaintances.

$(\mathrm{xxx})^{*}$ "Among” Abu, Aminah and Mei Lin are classmates.

The above insertion of 'between' before the names of two persons and 'among' before the names of three persons could be due to an over-generalization of certain structures in the target language. Malay learners could have had the experience of using the preposition 'between' before two persons' names, for example, 'There is a misunderstanding between Sally and Siva' and the preposition 'among' before three persons' names, for example, 'There is a misunderstanding among Aminah, Fatimah and Nadia”. When Malay learners made association with what they have learnt, there was a high tendency for them to apply the same rules to the above sentences without considering the different sentence contexts and meanings. This resulted in the formation of deviant structures as shown in (xxix) and (xxx).

The above finding show that although students have attained a certain level of proficiency in the target language, they have not fully mastered the use of some English prepositions especially those with diversified meanings and functions. This finding corresponds to [21]'s views that it is difficult for learners to master the use of English prepositions which have diverse usages and functions.

In this study, students seemed to find most difficulty in selecting the correct prepositions of time and place. The major cause of these prepositional errors was due to L1 interference. These errors deviated from the norms of target language as a result of transferring features peculiar from the Malay language to English. The next cause was overgeneralization whereby Malay students' familiarity with one form of a particular category of preposition in the target language led them to use the same form even in a different or inappropriate context. Another cause, though was not as common as the above two, was 'incomplete application of rules' which occurred when students applied some rules of the target language and neglected others. This difficulty could be contributed by the lack of knowledge, exposure, and limited experience in the application of these rules. The minor cause of errors was the ignorance of rule restriction by these Malay students. That is, students were not aware of the exceptions for some grammatical rules.

\section{CONCLUSION}

The present study has pedagogical implications. Before adopting the appropriate teaching method, it will be helpful for a language instructor/teacher to pay more attention to the 'problematic prepositions'. This error analysis which provides such information will help the teacher to decide which category of preposition to be given more priority or emphasis in the lesson. By knowing the causes of these errors, the teacher will be in a better position to adopt appropriate and effective teaching strategies to curb the negative transfer of mother tongue patterns to the target language and to overcome the difficulties inherent in the target language itself. Teachers can also incorporate the teaching of prepositions in the four language skills and the use of prepositions should be taught in context and not in isolation [22].

Another alternative is by using collocations whereby prepositions are taught using groups of words that tend to occur together. For example, instead of teaching the preposition 'at' and 'on' as a single entity, 'at your convenience' and 'on time' are taught (see [14], [23]). This study can be extended by investigating more categories/meanings of prepositions. In addition, a contrastive study can be carried out to compare the prepositional errors found in the written work of students from the three main races in Malaysia (Malay, Chinese and Indian students). It would be interesting to interview some students to obtain further insights as an accompanying data to the error analysis.

\section{REFERENCES}

[1] D. L. Loke, A. Juliana, and N. N. Z. Anthony, “A corpus based study on the use of preposition of time 'on' and 'at' in argumentative essays of form 4 and form 5 Malaysian students,” English Language Teaching, vol. 6, no. 9, pp. 128-135, 2013.

[2] A. Nasir, A. B. Maqsud, and H. Shafqat, "Error analysis: Learning articles and prepositions among secondary school students in Pakistan,” Interdisciplinary Journals of Contemporary Research in Business, vol. 2, no. 12, pp. 385-391, 2011.

[3] M. O. Olasehinde, "Error analysis and remedial pedagogy," in Language, Meaning and Society, S. T. Babatunde and D. S. Adeyanju, Eds. Ilorin, Itaytee Press and Publishing Co. (Nigeria), 2002.

[4] S. Hasyim, "Error analysis in the teaching of English," A Biannual Publication on the Study of Language and Literature, vol. 4, no. 1, pp. 62-74, 2002.

[5] S. P. Corder, Error Analysis, Interlanguage and Second Language Acquisition in Language Teaching and Linguistic, Survey, V. Kinsella, Ed. pp. 60-79. Cambridge University Press, 1978.

[6] P. S. Gill, "Error analysis as a basis for remedial teaching in Malay-medium schools in Malaysia," Thesis. United Kingdom: University of Manchester, 1974.

[7] S. H. Yap, "An investigation of errors in composition written by standard four, five and six children in primary school," M. Ed. dissertation, Kuala Lumpur, University of Malaya, 1973.

[8] A. R. N. Zainab, "The influence of the Malay language on the written English of selected U.K.M. students,” B.A. Thesis, Bangi, Universiti Kebangsaan Malaysia, 1986.

[9] Y. Y. Wong, "An investigation of errors in the written English compositions of Chinese form two students in a Malaysian school," B.A. Thesis. Bangi, Universiti Kebangsaan Malaysia, 1987. 
[10] H. Ngangbam, “An analysis of syntactic errors committed by students of English language class in the written composition of Mutah University: A case study,” European Journal of English Language, Linguistics and Literature, vol. 3, no. 1, pp. 1-13, 2016.

[11] P. Mennon, "An error analysis of social science students in a Malaysian university,” M.A. dissertation, Kuala Lumpur, University of Malaya, 1983.

[12] K. Phon, "Thai difficulties in using English prepositions," Language Learning, vol. 24, no. 2, pp. 75-87, 1984.

[13] M. C. Ravina, "An assessment of transitional language competence-A study of the Interaction of selected learners/learning variables," Unpublished doctoral dissertation, University of the Philippines, 1982.

[14] K. Lorincz and R. Gordon, "Difficulties in learning prepositions and possible solutions,” Linguistic Portfolios, vol. 1, no. 14, pp. 1-5, 2012.

[15] E. Koffi, Applied English Syntax: Foundations for Word, Phrase, and Sentence Analysis, Dubuque, Iowa: Kendall Hunt Publishing Company, 2010.

[16] J. C. Richards, Error Analysis: Perspective in Second Language Teaching, London, Longman, 1974.

[17] D. C. Bennett, Spatial and Temporal use of English Prepositions: An Essay in Stratificational Semantics, London, Longman, 1975.

[18] B. Hammerberg, "The insufficiency of error analysis," IRAL, vol. 12, no. 2, pp. 85-98, 1974.

[19] T. Tran, "Error analysis, constructive analysis and students' perception: A study of difficulty in second language learning," IRAL, vol. 8, no. 2, pp. 121-143, 1975.

[20] A. Saeed, S. Hussain, and S. Fatima, "Prepositional errors in the writings of Pakistani ESL students,” International Journal of English Linguistics, vol. 5, no. 3, pp. 120-128, 2015.

[21] X. Yu, "An analysis of prepositional error correction in TEM8 and its implications for FL learning," Theory and Practice in Language Studies, vol. 4, no. 3, pp. 624-630, 2014.

[22] M. Celce-Murcia and D. Larsen-Freeman, The Grammar Book: An ESL/EFL Teacher's Course, 2nd ed. USA: Heinle \& Heinle Publishers, 1999.

[23] C. M. Mueller, “English learners' knowledge of prepositions: Collocational knowledge or knowledge based on meaning?” System: An International Journal of Educational Technology and Applied Linguistics, vol. 39, no. 4, pp. 480-490.

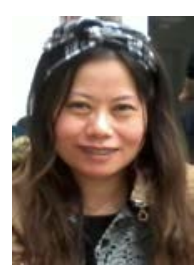

Chek K. Loi is presently a senior lecturer at Universiti Malaysia Sabah. She obtained her PhD degree in linguistics from University of Otago, Dunedin, New Zealand. She pursued her postdoctoral program in the United Kingdom in 2014. Dr. Loi has published papers in some international journals, namely Journal of Pragmatics, Journal of English for Academic Purposes, Discourse Studies, Iberica and
Sage Open. Her research interests include genre analysis, intercultural communication, bilingualism and discourse analysis.

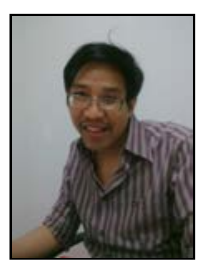

Songyut Akkakoson is an assistant professor of English at the Department of Languages, Faculty of Applied Arts, King Mongkut's University of Technology North Bangkok (KMUTNB), Thailand. He obtained his PhD in applied linguistics from the University of Otago, Dunedin, New Zealand. His research interests lie in learning styles, reading strategies, reading in EFL, English for business communication, English speaking anxiety, ESP genre analysis and World Englishes. Dr. Akkakoson's research interests include genre analysis, intercultural communication, bilingualism and discourse analysis.

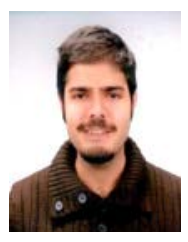

Mehmet Cem Odacioğlu was born on July 6, 1985 in Konya in Turkey. He received his B.A. from English translation and interpretation department at At1lım University, M.A. in translation studies from Hacettepe University and $\mathrm{PhD}$ from the same department at Sakarya University He is now working as a Dr. research assistant in the department of translation studies at Bartın University. His areas of research include translation theories, translation technologies, localization industry, linguistics, pragmatics, discourse analysis and applied translation studies.

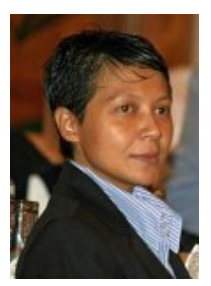

Norazah Mohd Suki is an associate professor at the Universiti Malaysia Sabah, Labuan International Campus, Malaysia. She has mentored several post-graduate students. Dr. Norazah has published papers in peer-review ISI and SCOPUS indexed journals, chapter books and international conference proceedings, and coordinated and participated in several research projects.

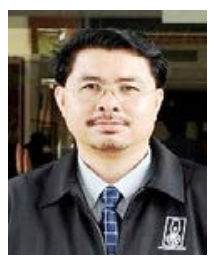

Henry Bating is currently teaching at Universiti Malaysia Sabah, Labuan International Campus. He is teaching Malay language to international students and Kadazandusun language to local students. He obtained his M. Ed. from Universiti Malaysia Sabah in 2012 and B.A (Hons) from Jakarta State University in 1997 in the field of teaching Indonesian language and literature. He has published papers in international journals and has written some books. Mr. Henry Bating's research interests are language and literature in Malay and Kadazandusun languages. 